\title{
AETIOLOGY AND CONTROL OF CARDIOVASCULAR REACTIONS DURING TRANS-SPHENOIDAL RESECTION OF PITUITARY MICROADENOMAS
}

\author{
Mounir N. Abou-Madi, Davy Trop and Jennifer Barnes
}

ABstract

Two groups of 12 patients were studied to determine the causes of hypertension during trans-sphenoidal resection of pituitary microadenomas. Two concentrations of lidocaine, 0.5 and 1.0 per cent with epinephrine $1 / 200,000$, were used to infiltrate the nose and upper gingiva. Heart rate, electrocardiogram lead II and systolic and diastolic arterial blood pressures were monitored. Three stages were observed for changes in above parameters: nasal infiltration, nasal dissection and sellar exploration. Highly significant reductions in arterial blood pressure and pulse rate responses to infiltration and nasal dissection were achieved by increasing the lidocaine concentration used for infiltration from 0.5 to 1.0 per cent $(p<0.05)$. Our findings implicate reflex from nasal stimulation as the main cause of the adverse cardiovascular effects. Only minimal changes accompanied the progress of the intrasellar dissection in both groups.

POTENT CARDIOVASCULAR RESPONSES are known to be evoked by stimulation of the nose, the afferent pathway being branches of the trigeminal nerve. ${ }^{t}$ Severe cardiovascular reactions have been reported associated with trans-sphenoidal pituitary microsurgical procedures. ${ }^{2}$ The hypertension that follows is usually severe and uncontrollable, causing increased bleeding which obscures microscopic details of the sellar region. It is difficult for the surgeon to locate the small intrapituitary adenomas; should he excise too much tissue, anterior pituitary function will be affected. It is therefore extremely important that a dry and bloodless surgical field be secured. We studied the effect of epinephrine solutions containing two different concentrations of lidocaine, infiltrated locally, on the cardiovascular responses to transethmoidal, trans-sphenoidal resection of pituitary microadenomas.

\section{Methods}

Twenty-four ASA class I female patients scheduled for trans-sphenoidal resection of prolactin-secreting tumours were studied. Their

Mounir N. Abou-Madi, M.D., F.R.C.P.(C), Assistant Professor, McGill Univeristy; Departments of Anaesthesia and Neurology and Neurosurgery. Davy Trop, M.D., F.R.C.P.(C), Associate Professor, McGill University; Departments of Anaesthesia and Neurology and Neurosurgery, Chief, Department of Anaesthesia. Jennifer Barnes, M.D., C.S.P.Q., Lecturer in Anaesthesia. McGill University; Departments of Anaesthesia and Neurology and Neurosurgery. Department of Anaesthesia, Montreal Neurological Hospital and Institute, 3801 University Street, Montreal, Quebec, Canada, H3A 2B4. M.D.

Address communications to: M.N. Abou-Madi, ages ranged from 20 to 62 years. All patients had endocrine testing, normal thyroid assay, and received appropriate preoperative steroid therapy. No premedication was ordered. In the induction room, a 16-gauge peripheral intravenous cannula was inserted for volume infusion, and a blood pressure cuff and electrocardiograph electrodes were attached. Atropine sulphate $0.4 \mathrm{mg}$, was injected intravenously. The patients were then anaesthetized with droperidol $10 \mathrm{mg}$, fentanyl $0.080-0.100 \mathrm{mg}$ and thiopentone sodium $250-300$ $\mathrm{mg}$, all given intravenously. Tracheal intubation was facilitated with succinylcholine $80 \mathrm{mg}$ injected intravenously. A size 8 reinforced tracheal tube was inserted and the oropharynx was packed with wet cotton gauze to prevent aspiration of blood. Subsequent anaesthesia and muscle relaxation were achieved with fentanyl 0.040 $\mathrm{mg}$, intravenously, every 30 minutes, 70 per cent nitrous oxide with oxygen, and d-tubocurarine 6 $\mathbf{m g}$, intravenously, every 30 minutes. The lungs were ventilated mechanically using a Bain circuit and fresh gas flow adjusted to achieve a $\mathrm{Pa}_{\mathrm{CO}_{2}}$ level of $4-4.79 \mathrm{kPa}$ (30 to 36 torr). A number 20 radial artery cannula was inserted for continuous arterial blood pressure recording and for arterial blood sampling. Patients were positioned in a semi-sitting position and transferred to the operating room.

The patients were divided into two consecutive groups of twelve. Age, weight, $\mathrm{Pa}_{\mathrm{CO}_{2}}$ and duration of nasal dissection were statistically comparable. Intrasellar exploration time, however, because it was largely determined by surgical accessibility of the tumour, differed among patients of the same group.

In group A patients a 0.5 per cent lidocaine

Canad. Anaesth. Soc. J., vol. 27, no. 5, September 1980 
TABLE I

Mean Maximal Changes in Systolic Blood Pressure: Analysis of Variance

\begin{tabular}{|c|c|c|c|c|c|c|}
\hline \multirow[b]{2}{*}{ Challenge } & \multirow{2}{*}{$\begin{array}{c}\text { Lidocaine with } \\
1 / 200,000 \text { epinephrine } \\
(\%)\end{array}$} & \multicolumn{2}{|c|}{$\begin{array}{l}\text { Mean systolic blood } \\
\text { pressure }\end{array}$} & \multirow[b]{2}{*}{ Mean difference } & \multirow[b]{2}{*}{ F value } & \multirow[b]{2}{*}{ Pvalue } \\
\hline & & Pre & Post & & & \\
\hline Lidocaine & 0.5 & 119.75 & 164.16 & -44.41 & & \\
\hline Infiltration & 1.0 & 111.66 & 128.75 & -17.08 & 16.36 & $0.0005 \dagger$ \\
\hline Nose & 0.5 & 122.08 & 168.33 & -46.25 & & \\
\hline Dissection & 1.0 & 108.33 & 120.83 & -12.50 & 20.44 & $0.0002 \uparrow$ \\
\hline Pituitary & 0.5 & 133.33 & 143.33 & -10.00 & & \\
\hline Exploration & 1.0 & 112.91 & 113.75 & -0.84 & 3.65 & $0.0693^{*}$ \\
\hline
\end{tabular}

Group $A(n=12)$ infiltrated with 0.5 per cent lidocaine in $1 / 200,000$ epinephrine.

Group $B(n=12)$ infiltrated with 1.0 per cent lidocaine in $1 / 200,000$ epinephrine.

$* \mathrm{P}<0.10$.

$\uparrow \mathrm{P}<0.05$.

TABLE II

Mean Maximal Changes in Diastolic Blood Pressure: Analygis of Variance

\begin{tabular}{|c|c|c|c|c|c|c|}
\hline \multirow[b]{2}{*}{ Challenge } & \multirow{2}{*}{$\begin{array}{c}\text { Lidocaine with } \\
\text { 1/200,000 epinephrine } \\
\text { (\%) }\end{array}$} & \multicolumn{2}{|c|}{$\begin{array}{c}\text { Mean diastolic blood } \\
\text { pressure }\end{array}$} & \multirow[b]{2}{*}{ Mean difference } & \multirow[b]{2}{*}{ F value } & \multirow[b]{2}{*}{ P value } \\
\hline & & Pre & Post & & & \\
\hline Lidocaine & 0.5 & 74.16 & 100.00 & -25.84 & & \\
\hline Infiltration & 1.0 & 66.66 & 74.58 & -7.92 & 12.06 & $0.0022 \dagger$ \\
\hline Nose & 0.5 & 76.66 & 96.66 & -20.00 & & \\
\hline Dissection & 1.0 & 67.91 & 72.50 & -4.59 & 10.55 & $0.0037 \dagger$ \\
\hline Pituitary & 0.5 & 80.83 & 84.58 & -3.75 & & \\
\hline Exploration & 1.0 & 70.00 & 68.33 & +1.67 & 2.25 & 0.1480 \\
\hline
\end{tabular}

Group $A(n=12)$ infiltrated with 0.5 per cent lidocaine in $l / 200,000$ epinephrine.

Group $A(n=12)$ infiltrated with 1.0 per cent lidocaine in $1 / 200,000$ epinephrine.

${ }^{*} \mathbf{P}<0.10$

$\dagger \mathrm{P}<0.05$.

TABLE III

Mean Maximal Changes in Pulse Rate: Analysis of Variance

\begin{tabular}{|c|c|c|c|c|c|c|}
\hline \multirow[b]{2}{*}{ Challenge } & \multirow{2}{*}{$\begin{array}{c}\text { Lidocaine with } \\
1 / 200,000 \text { epinephrine } \\
(\%)\end{array}$} & \multicolumn{2}{|c|}{ Mean pulse rate } & \multirow[b]{2}{*}{ Mean difference } & \multirow[b]{2}{*}{ F value } & \multirow[b]{2}{*}{ P value } \\
\hline & & Pre & Post & & & \\
\hline Lidocaine & 0.5 & 81.16 & 104.16 & -23.00 & & \\
\hline Infiltration & 1.0 & 73.00 & 84.91 & -11.91 & 3.29 & $0.0835^{*}$ \\
\hline Nose & 0.5 & 78.08 & 89.83 & -11.75 & & \\
\hline Dissection & 1.0 & 71.83 & 72.83 & -1.00 & 7.39 & 0.0125 \\
\hline Pituitary & 0.5 & 82.91 & 82.50 & +0.41 & & \\
\hline Exploration & 1.0 & 74.00 & 70.75 & +3.25 & 0.96 & 0.3375 \\
\hline
\end{tabular}

Group $A(n=12)$ infiltrated with 0.5 per cent lidocaine in $1 / 200,000$ epinephrine.

Group B $(n=12)$ infiltrated with 1.0 per cent lidocaine in $1 / 200,000$ epinephrine.

$m P<0.10$

$+\mathrm{P}<0.05$

solution containing epinephrine in a $1 / 200,000$ concentration was used to infiltrate the nasal mucosa, the upper gingiva, the nasal septum, and the floor of the nose.

In group B patients a one per cent lidocaine solution containing epinephrine $1 / 200,000$ was used to infiltrate the same areas. The volume injected, determined solely by the surgical need, was the same in both groups and amounted to an average of $35 \mathrm{ml}$ of solution. To ensure uni- 
formity, all nasal infiltrations and pituitary explorations were carried out by the same surgeon.

Heart rate, electrocardiogram lead II, and systolic and diastolic arterial blood pressures were recorded continuously on all patients at the following stages:

(1) immediately before, during, and for ten minutes after nasal infiltration;

(2) before and at the start of the nasal dissection;

(3) before and during the microsurgical exploration of the sella turcica.

The results for each group were compared by analysis of variance. $(P<0.05$ was regarded as significant.)

\section{Results}

Tables I, II, and III show mean maximal blood pressure and pulse rate changes in groups $A$ and $B$ with analysis of their mean differences. Figures 1 and 2 illustrate their mean percentage changes from control levels.

Following nasal infiltration of the epinephrine solution containing lidocaine 0.5 per cent, group A patients showed an immediate and marked elevation in arterial blood pressure. Pressure returned to pre-infiltration levels within three to five minutes. Group B patients, however, who received the higher percentage of lidocaine, registered far less change in arterial blood pressure following infiltration ( $p<0.05$ ). Marked tachycardia occurred in group A patients at this point; less significant tachycardia occurred in group $B$ patients $(\mathrm{p}<0.10)$.

There were also marked differences between the two groups during nasal dissection. In group A patients a marked elevation in both arterial blood pressure and pulse rate occurred again, resulting in increased vascular ooze from mucosa and bone. To control this hypertension it was necessary to give nine of the twelve patients intermittent intravenous infusions of nitroglycerin at a rate of 0.1 to $0.3 \mathrm{mg}$ per minute. An average of $15 \mathrm{mg}$ was infused over a mean period of 40 minutes.

In group B patients, however, there was much less change in arterial blood pressure and pulse rate during nasal dissection $(\mathrm{p}<0.05)$. Group $B$ patients remained, ultimately, normotensive (Tables I and II).

Exploration of the sella turcica resulted in less significant arterial blood pressure changes in both groups. Group B patients, however, registered a
Mean Percentage Changes from Control

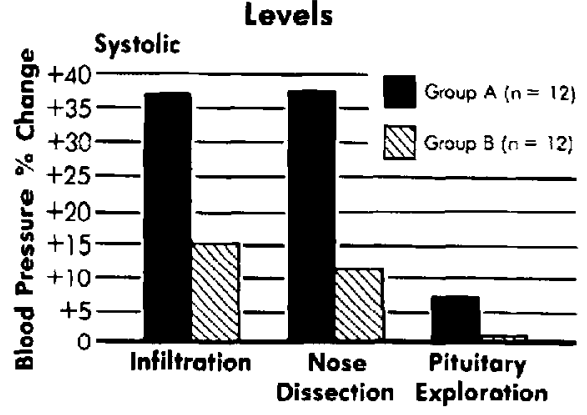

Diastolic

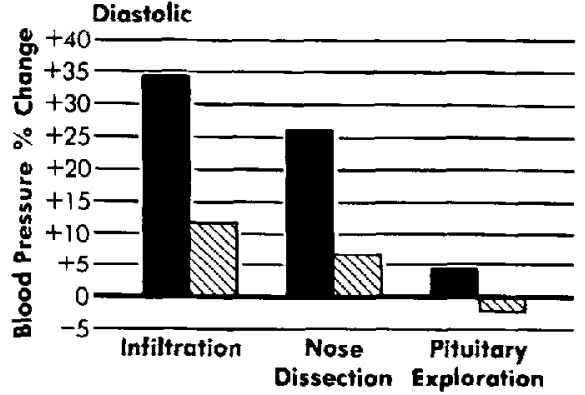

FIGURE 1 Comparison of mean percentage changes in systemic arterial blood pressure following nasal infiltration, nasal dissection, and pituitary exploration in groups $A$ and $B$ patients.

\section{Mean Percentage Changes from Control}

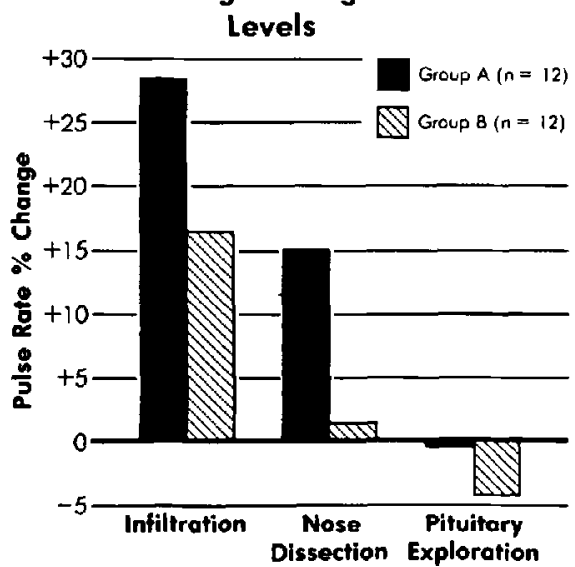

Figure 2 Comparison of mean percentage changes in pulse rate following nasal infiltration nasal dissection, and pituitary exploration in groups $\mathrm{A}$ and $\mathrm{B}$ patients.

lesser rise $(\mathrm{p}<0.10)$ in response to pituitary exploration (Tables I and II). In both groups the pulse rate remained practically unchanged at this stage (Table III). 


\section{Discussion}

Refined microsurgical techniques, videomonitoring and image amplification have all made the trans-sphenoidal approach to pituitary adenomas a procedure of choice. ${ }^{3}$ The present study, however, demonstrates that significant cardiovascular reactions to surgical stimulation occur at three distinct stages of the procedure: first, immediately following injection of epinephrine; second, in response to nasal stimulation; and third, throughout pituitary exploration. Our data suggest that adequate local anaesthesia of the nasal mucosa is effective in preventing cardiovascular responses to nasal dissection.

To achieve haemostasis and to help in the dissection of the nasal mucosa, submucosal injection of local anaesthetic solutions containing epinephrine is widely used. To protect against cardiovascular reactions to the epinephrine, lidocaine has specifically been added to the solution. ${ }^{4}$ Our data suggest that lidocaine in sufficient concentration does counteract the cardiovascular side-effects of epinephrine. Patients infiltrated with 1.0 per cent lidocaine with $1 / 200,000$ epinephrine maintained their arterial blood pressure at normotensive levels. This protection, however, was not achieved in group A patients who received only 0.5 per cent lidocaine. Epinephrine is presumably taken into the blood stream very rapidly through the nasal mucosa. A higher concentration of lidocaine is accordingly needed to counteract the cardiovascular effects of epinephrine. At least three mechanisms might be invoked to explain why patients who received the lesser concentration of lidocaine maintained elevated arterial blood pressure during nasal dissection. First, general anaesthesia affords no protection against the potent cardiovascular responses evoked by the surgical stimulation of the nose. Second, lidocaine 0.5 per cent is apparently insufficient to block the afferent pathways. Third, epinephrine-induced hypersensitivity possibly results in an enhanced response to noxious reflexes. In addition, a high blood lidocaine concentration may also offer systemic protective effects: this is now being investigated at our institute.

It will be noted that in group A patients arterial blood pressure did not return to control levels at the end of the dissection phase. The vasodilating antihypertensive drugs including hydralazine, diazoxide, and sodium nitroprusside stimulate renin release by a combination of mechanisms. ${ }^{5}$
Although no data have yet implicated nitroglycerin as having a similar effect, the failure of the arterial blood pressure to return to control levels may result from nitroglycerin administered to control hypertension. The vasodilator may, in fact, have induced an increase in plasma renin activity (Tables I and II). Our findings add to the evidence implicating reflex from nasal stimulation as a cause of adverse cardiovascular effects. There is no evidence that prolactin-secreting tumours themselves induce cardiovascular reactions during their microsurgical excision. ${ }^{6}$

Although hypertension may be of no clinical significance to the patients, increased bleeding will undoubtedly jeopardize an otherwise successful and elegant microsurgical procedure.

In conclusion, we believe that intranasal local anaesthesia has proved to be a successful adjunct to general anaesthesia in suppressing noxious stimuli. Enough lidocaine must be added to epinephrine-containing solutions, however, to achieve complete intranasal anaesthesia, and to guard against ventricular dysrhythmias. Such a procedure promotes relaxed surgical conditions and obviates the necessity to control hypertension during the operation.

\section{ACKNOWLEDGEMENTS}

The authors are indebted to Dr. D. Thomas and Miss T. Wolfson, department of Epidemiology, McGill University, for statistical analysis; to Miss V. Lees for editorial assistance, and to Miss J. Jolicoeur for typing the manuscript.

\section{REFERENCES}

1. Allison, D. J. Correspondence. Reflexes from the nose. N. Engl. J. Med. 299: 1468 (1978).

2. Messick, J. M., JR., Laws, E.R., Jr \& Abboud, C. F. Anesthesia for trans-sphenoidal surgery of the hypophyseal region. Anesth. \& Analg. 57: 206 (1978).

3. DANIEL, R. K. Microsurgery: through the looking glass. N. Engl. J. Med. 300: 1251 (1979).

4. Horrigan, R. W. Eger, E. I. \& Wilson, C. Epinephrine-induced arrhythmias during enflurane anesthesia in man: a nonlinear dose-response relationship and dose-dependent protection from lidocaine. Anesth. \& Analg. 57: 547 (1978)

5. OPARIL, S. \& HABER, E. The renin-angiotensin system (first of two parts). N. Engl. J. Med. 291: 389 (1974).

6. Frantz, A. G. Prolactin. N. Engl. J. Med. 298: 201 (1978). 


\section{RÉSUMÉ}

La résection chirurgicale de microadénomes hypophysaires par une approche trans-sphénoidale provoque des poussées de tachycardie et d'hypertension inopportunes, occasionnées principalement par la stimulation de la muqueuse nasale et gingivale. Ces réactions réflexes ne sont pas maitrisées par l'infiltration d'une solution à 0.5 pour cent de lidocaine et épinephrine à $1 / 200,000$. Par contre, l'utilisation d'une solution à 1 pour cent de lidocaine et épinephrine à 1/200,000 contrôle les effets cardiovasculaires durant l'infiltration, la dissection nasale et la résection intrasellaire. 